\title{
Competition from unseen or unheard novel words: Lexical consolidation across modalities
}

\author{
Iske Bakker $^{\mathrm{a}, \mathrm{b}, *}$, Atsuko Takashima ${ }^{\mathrm{a}, \mathrm{b}}$, Janet G. van Hell ${ }^{\mathrm{c}, \mathrm{a}}$, Gabriele Janzen ${ }^{\mathrm{a}, \mathrm{b}}$, \\ James M. McQueen ${ }^{\mathrm{a}, \mathrm{b}, \mathrm{d}}$ \\ ${ }^{a}$ Radboud University Nijmegen, Behavioural Science Institute, P.O. Box 9104, 6500 HE Nijmegen, The Netherlands \\ ${ }^{\mathrm{b}}$ Radboud University Nijmegen, Donders Institute for Brain, Cognition and Behaviour, P.O. Box 9101, 6500 HB Nijmegen, The Netherlands \\ c Pennsylvania State University, Department of Psychology, University Park, PA 16802, USA \\ ${ }^{\mathrm{d}}$ Max Planck Institute for Psycholinguistics, Nijmegen, P.O. Box 310, 6500 AH Nijmegen, The Netherlands
}

\section{A R T I C L E I N F O}

\section{Article history:}

Received 28 August 2013

revision received 28 February 2014

\section{Keywords:}

Word learning

Memory consolidation

Complementary Learning Systems (CLS)

Lexical competition

Modality

Cross-modal representation

\begin{abstract}
A B S T R A C T
In four experiments we investigated the formation of novel word memories across modalities, using competition between novel words and their existing phonological/orthographic neighbours as a test of lexical integration. Auditorily acquired novel words entered into competition both in the spoken modality (Experiment 1) and in the written modality (Experiment 4) after a consolidation period of $24 \mathrm{~h}$. Words acquired from print, on the other hand, showed competition effects after $24 \mathrm{~h}$ in a visual word recognition task (Experiment 3) but required additional training and a consolidation period of a week before entering into spoken-word competition (Experiment 2). These cross-modal effects support the hypothesis that lexicalised rather than episodic representations underlie post-consolidation competition effects. We suggest that sublexical phoneme-grapheme conversion during novel word encoding and/or offline consolidation enables the formation of modality-specific lexemes in the untrained modality, which subsequently undergo the same cortical integration process as explicitly perceived word forms in the trained modality. Although conversion takes place in both directions, speech input showed an advantage over print both in terms of lexicalisation and explicit memory performance. In conclusion, the brain is able to integrate and consolidate internally generated lexical information as well as external perceptual input.
\end{abstract}

(c) 2014 Elsevier Inc. All rights reserved.

\section{Introduction}

As anyone who has ever attempted to learn a foreign language knows, successful storage of novel words is one of the keys to achieve competence. Furthermore, although the basis of our native language vocabulary is built during childhood, even word learning in our first language continues throughout life. We constantly enrich our mental lexicons as our environment presents us with neologisms,

\footnotetext{
* Corresponding author. Address: Donders Centre for Cognitive Neuroimaging, Kapittelweg 29, 6525 EN Nijmegen, The Netherlands.

E-mail address: i.bakker@pwo.ru.nl (I. Bakker).
}

loanwords, or specialist terminology. While some of these novel words will first be encountered in speech, others are acquired in print, and some may never even be perceived in the other modality. It seems reasonable to assume, however, that the modality in which a word was initially acquired at some point in time ceases to influence lexical processing. For example, an individual may have learned the word hippopotamus ${ }^{1}$ in its spoken form as a child, and first encountered the printed word hippocampus in a neuroscience textbook. This presumably does not stop these

\footnotetext{
${ }^{1}$ Example from Henderson, Weighall, and Gaskell (2013).
} 
form-overlapping words from entering into lexical competition with each other, perhaps not even if this individual has never yet heard the spoken form of hippocampus. The present study explores if and how such cross-modal effects arise by investigating the role of modality in novel word learning.

One of the most astonishing features of first language vocabulary acquisition is the speed with which novel items are encoded: children excel at 'fast mapping' sounds to meanings (Carey \& Bartlett, 1978). Adults appear to be capable of similarly rapid vocabulary acquisition, at least under certain circumstances. Indeed, Saffran, Newport, Aslin, Tunick, and Barrueco (1997) found young adults and first-grade children to be equally skilled at segmenting and storing novel words from a string of nonsense syllables in an incidental learning task. More recently, Shtyrov, Nikulin, and Pulvermüller (2010) reported a neurophysiological counterpart of these behavioural findings on the early stages of word learning. After as little as $14 \mathrm{~min}$ of passive listening, neural response patterns to novel words became qualitatively identical to those elicited by existing words, suggesting that memories of the novel words had been established.

While both children and adults are thus clearly able to form representations of novel words after minimal exposure, these findings do raise the question whether such rapidly created memories are of the same nature as the rich, stable, highly interconnected representations that constitute the mental lexicon. A recent line of research suggests that this is not the case, but that rapidly stored novel word memories and existing lexical representations initially rely on different memory systems with distinct neural substrates. Only after a post-learning consolidation period, during which they are integrated with the existing lexicon, are novel words thought to have acquired truly word-like properties and hence to be fully 'lexicalised' (Davis \& Gaskell, 2009; Gaskell \& Dumay, 2003).

According to the Complementary Learning Systems (CLS) framework (McClelland, McNaughton, \& O’Reilly, 1995), this consolidation mechanism has its neural basis in the interaction between the medial temporal lobe, most importantly the hippocampus, and the neocortical memory system. The hippocampus serves as a fast-learning, temporary storage area, encoding novel information in a sparse and episodic fashion. Following encoding, a slower neocortical learning process takes place during which novel memories are integrated into the existing, widely distributed memory network. The latter process is thought to rely heavily on memory reactivation during sleep (e.g., Rasch, Büchel, Gais, \& Born, 2007; Wilson \& McNaughton, 1994). Thus, by gradually interleaving new and old information post-learning, the CLS account solves the problem of catastrophic interference (McCloskey \& Cohen, 1989).

Successful memory integration is especially relevant in the context of word learning. Whereas tasks that simply measure recall or recognition of novel words may be performed based on the retrieval of purely episodic, non-lexical memory traces, the ability of those novel words to interact with the existing lexicon would be evidence that cortical, lexical representations have been formed. For example, a phenomenon central to most theories of spoken word recognition is lexical competition: a set of multiple candidates that match the incoming acoustic signal compete for selection, thus slowing down recognition of the target (McQueen, Norris, \& Cutler, 1994). As argued by Gaskell and Dumay (2003), the ability of a novel word to enter into lexical competition with its existing neighbours can therefore be considered a strong test of lexical integration.

To test the hypothesis that lexical integration requires offline consolidation, Gaskell and Dumay (2003) familiarised subjects with spoken novel words (e.g., cathedruke) which overlapped phonologically with existing base words (e.g., cathedral). Immediately after training and on several subsequent days, subjects made speeded responses to the existing base words and control words in a lexical decision task. Reaction times to the existing base words increased, but only after a consolidation period of several days, suggesting that offline consolidation indeed plays a role in word learning. Certain paradigms, including Hebbian learning (Szmalec, Page, \& Duyck, 2012) and interleaved training of novel and existing neighbour words (Lindsay \& Gaskell, 2013), have been shown to evoke lexical competition effects within a single day in the absence of sleep. Nonetheless it is evident that, like non-linguistic memory consolidation, novel word integration is facilitated by offline consolidation and particularly sleep (Dumay \& Gaskell, 2007; Tamminen, Payne, Stickgold, Wamsley, \& Gaskell, 2010).

Although most work on novel word integration has used auditory paradigms, consolidation effects have also been observed in visual word recognition. Bowers, Davis, and Hanley (2005) taught participants novel word forms in a typing task, and subsequently measured reaction times to existing orthographic neighbours in a semantic decision task. As in the spoken-word literature, robust competition effects emerged only after a delay (in this case of $24 \mathrm{~h}$ ). In a picture naming paradigm, Clay, Bowers, Davis, and Hanley (2007) furthermore observed a consolidationdependent interference effect when meaningful, visually acquired novel words were superimposed on semantically related pictures. Thus, at least when training and test modalities are consistent, consolidation effects occur both in spoken and printed word recognition. However, little is known about how these different modalities interact during encoding and consolidation of novel words.

Most current models of the bimodal lexicon assume a modality-specific word-form level that contains autonomous orthographic and phonological representations. These nodes have independent connections to the semantic level, that is, they are activated in parallel rather than serially (e.g., Caramazza, 1997; Grainger \& Ferrand, 1994). This autonomy of representation does not imply isolation in processing, however: cross-modal connections are thought to link phonology and orthography at one or more processing levels. For example, in the Bimodal Interactive Activation model (Ferrand \& Grainger, 2003; Grainger \& Ferrand, 1994) phonological and orthographic representations of the same word are linked both through direct lexical facilitatory connections and by means of a sublexical bidirectional grapheme-phoneme conversion mechanism. Activation can spread cross-modally through these connections, and word recognition in both modalities should thus be affected by orthographic and phonological information. 
A wealth of evidence suggests that phonology and orthography indeed interact, and do so in a highly symmetrical manner. It has long been established that printed word recognition involves phonological activation, even in exclusively visual tasks. For example, phonological neighbourhood density has been shown to influence visual word recognition (Grainger, Muneaux, Farioli, \& Ziegler, 2005; Yates, Locker, \& Simpson, 2004). Facilitation effects from briefly presented, masked homophonic pseudoword primes (mayd-MADE) furthermore suggest that this phonological involvement in reading is extremely rapid (Rastle \& Brysbaert, 2006). Phonological activation is estimated to lag a mere $20-30 \mathrm{~ms}$ behind orthographic activation (Ferrand \& Grainger, 1992; Ziegler, Ferrand, Jacobs, Rey, \& Grainger, 2000), and is as such unlikely to rely on strategic factors.

Perhaps more surprisingly, given the primacy of speech, there is also abundant evidence that orthographic information plays an important role in spoken word processing. For instance, orthographic neighbourhood density has been found to affect spoken word recognition (Ziegler, Muneaux, \& Grainger, 2003). Words with many orthographic neighbours were recognised faster, a pattern which the authors argue arises from a lexical-sublexical feedback loop. Furthermore, analogous to the results observed in visual word recognition, priming effects in auditory tasks are modulated by orthographic overlap even when conscious processing of primes is minimised (Chéreau, Gaskell, \& Dumay, 2007; Slowiaczek, Soltano, Wieting, \& Bishop, 2003; Taft, Castles, Davis, Lazendic, \& Nguyen-Hoan, 2008). These findings strongly suggest that orthographic information becomes available rapidly and automatically during spoken word recognition.

This bimodal involvement in lexical processing raises the question of whether modality-specific representations can be formed without perceptual input in that modality. Given that visual word input results in the retrieval of sublexical phonological representations, this internally generated pattern of activation may be neurally similar to the pattern evoked by actual speech input. If this is the case, print input could give rise to a lexical representation in the spoken modality, just like spoken input would. Similarly, speech input could be hypothesised to lead to the formation of orthographic as well as phonological representations. The present study aims to test whether such cross-modal learning indeed takes place, and if so, how it is affected by offline consolidation.

To date, only one published study explicitly looking at lexical integration includes a modality shift between training and test (Szmalec et al., 2012). In this experiment participants were exposed to novel word forms in a Hebbian learning task, which involved recall of visually presented syllable sequences in which orthographic and phonological neighbours of existing words were embedded. After a 12-h delay, competition effects emerged in an auditory pause detection task. Although this study provides a first indication that novel words acquired in one modality engage in lexical competition in the other, it remains unknown what the relative effect of input and test modality is on the magnitude of competition effects and the time-course of consolidation. In the current series of experiments we orthogonally varied training and test modality in order to compare lexicalisation in speech and print directly.

Experiment 1 aimed to replicate, in Dutch, the competition effects observed in previous studies of novel spoken word consolidation (Davis, Di Betta, MacDonald, \& Gaskell, 2009; Dumay \& Gaskell, 2007, 2012; Gaskell \& Dumay, 2003; Tamminen \& Gaskell, 2008). In an auditory-only paradigm, novel words were hypothesised to slow down recognition of their existing neighbours after $24 \mathrm{~h}$. In Experiment 2, we asked whether lexicalised phonological representations can be formed cross-modally, that is, based only on visual exposure to novel words. In Experiment 3, training and test were both administered visually, allowing for a direct comparison of the effect of visual exposure within versus between modalities. Experiment 4 examined the symmetry of cross-modal effects by combining auditory training with a visual competition task, testing the idea that automatic retrieval of orthographic information during spoken word processing may lead to the formation of orthographic representations in the absence of printed input.

\section{Experiment 1}

Experiment 1 tested the hypothesis that novel words enter into lexical competition with phonologically overlapping existing words, but only after a 24-h consolidation period including overnight sleep (e.g. Dumay \& Gaskell, 2007). Furthermore, these effects were expected to strengthen after a second training session and a subsequent consolidation period of one week.

\section{Method}

\section{Participants}

Twenty-six monolingual native Dutch-speaking participants (four males) with no known hearing, learning or language disorders, aged 18-26 (mean 20), were recruited from the university subject pool. They received course credit or were paid for their participation.

\section{Materials}

The stimulus set was designed to be a Dutch analogue of the set used by Gaskell and Dumay (2003) in English. Novel word stimuli were 40 trisyllabic pseudowords which diverged phonologically from an existing Dutch word (the 'base word') at the penultimate phoneme (e.g. kathedrook kathedraal, cf. Gaskell and Dumay's cathedruke - cathedral). Novel and base words were 6-9 phonemes long (mean 7.4) and the existing word CELEX frequencies (Baayen, Piepenbrock, \& Gullikers, 1995) ranged from 1 to 29 per million (mean 7.2). The uniqueness point of the base word, the phoneme at which the word becomes uniquely identifiable, was always located before the phonemic divergence with the novel word (position 3-6, mean 4.9). Thus, the novel word effectively shifted the uniqueness point of its base word to the penultimate phoneme, that is, towards the end of the word. Stimulus pairs were divided into two lists matched precisely on length, frequency and uniqueness point, and were counterbalanced across participants. The 
set of novel words and their base words is listed in the Appendix.

\section{Procedure}

The experiment consisted of three sessions. On day 1, participants completed 36 blocks of a phoneme monitoring test (as in Gaskell \& Dumay, 2003). Each of the 20 novel words occurred once in each block, giving a total of 720 trials. Trial order was randomised anew for each block. Before the start of each block, a target phoneme was presented auditorily (e.g. ' $[b ə]$ as in bat') and the participant's task was to press a button whenever the target phoneme occurred in a word. Six different target phonemes $(/ \mathrm{p} /, / \mathrm{t} /$, $/ \mathrm{b} /, / \mathrm{l} /, / \mathrm{k} /, / \mathrm{n} /)$ were used, with each phoneme serving as the target in six non-consecutive blocks. Each block contained 4-12 (average 7) target-present trials. Feedback was provided after each trial. Following Gaskell and Dumay (2003), participants were informed that they would be tested on their memory for the novel words, but no further information about the nature of the memory tests was given. Thus, learning was intentional but no specific strategies were encouraged.

After the training phase, a pause detection task (as in Gaskell \& Dumay, 2003) was administered. This task was designed to measure lexical competition of novel neighbours with their existing neighbours, based on the finding that increased onset density leads to slower reaction times in this task (Mattys \& Clark, 2002). Stimuli consisted of the existing neighbours of the trained novel words, the neighbours of the untrained novel words, and $60 \mathrm{bi}-$ and trisyllabic existing word fillers. Thus, half of the experimental items had acquired a novel neighbour (e.g., kathedraal acquired the novel neighbour kathedrook), whereas the onset density of the other half had not changed.

Half of the words in each condition (including fillers) contained a $200-\mathrm{ms}$ pause, inserted before the final syllable. For each stimulus, participants indicated the absence or presence of a pause by pressing one of two buttons, with a Reaction Time (RT) limit of $2000 \mathrm{~ms}$ and an inter-trial interval of $1000 \mathrm{~ms}$. The allocation of words to the pauseabsent and pause-present conditions was counterbalanced across participants. RTs were measured from the onset of the pause or, for the pause-absent trials, from a marker representing the onset of the pause in the pause-present counterpart of the item. Trial order was randomised anew for each participant.

Finally, novel word memory was assessed using both a free recall and a recognition task. In the free recall task, participants were asked to name as many novel words as they remembered within three minutes. Recognition was tested using a two-alternative forced-choice (2AFC) task, in which participants were presented auditorily with twenty novel word pairs in randomised order. Each pair consisted of a trained novel word and a foil which differed from the trained item on one phoneme. Participants indicated which novel word they had heard in the training phase by pressing one of two buttons. There was no time pressure in this task.

Participants returned for the second session on the following day (day 2), approximately $24 \mathrm{~h}$ later. They performed the pause detection and novel word memory tasks as on day 1 , followed by 12 additional blocks of phoneme monitoring. The third session (day 8) took place exactly a week after day 1 . The pause detection and novel word memory tasks were administered as in the previous two sessions.

\section{Results}

Performance in the phoneme monitoring task was good (1.5\% misses, $1.3 \%$ false alarms).

The error rate in the pause detection task was low overall (3.5\%), but slightly higher for base words of trained novel words compared to the control condition $(F(4,26)=4.657, p=.04)$. No effect of day on accuracy was observed. Errors (3.5\%) and RTs below $200 \mathrm{~ms}$ or above $1700 \mathrm{~ms}$ (2.5\%) were removed from the pause detection data for reaction time analysis. Pause-present and pauseabsent trials were collapsed. Here and in the following experiments, Greenhouse-Geisser-corrected degrees of freedom and $p$-values are reported whenever assumptions of sphericity were violated. By-subjects $\left(F_{1}\right)$ and by-items $\left(F_{2}\right)$ statistics are reported.

Across days, responses to base words that had acquired a novel competitor were overall slower than responses to control base words (757 versus $693 \mathrm{~ms}$, an effect of $61 \mathrm{~ms}$ ), suggesting that novel words entered into competition with their existing neighbours. This difference increased from $19 \mathrm{~ms}$ on day 1 to $50 \mathrm{~ms}$ on day 2 and $109 \mathrm{~ms}$ in the final session (see Table 1 and Fig. 1).

A repeated-measures ANOVA with factors Day $(1,2,8)$ $\times$ Condition (trained, control) revealed a main effect of Condition, confirming that RTs were overall slower to neighbours of trained novel words than to neighbours of untrained control words $\left(F_{1}(1,25)=25.782, p=.001\right.$; $\left.F_{2}(1,39)=30.319, p=.001\right)$. A main effect of Day was also observed $\left(F_{1}(2,50)=14.111, p=.001 ; F_{2}(2,78)=40.052\right.$, $p=.001$ ), reflecting an overall increase in RTs over days. The crucial interaction with Day was significant $\left(F_{1}(2,50)=5.189, \quad p=.009 ; \quad F_{2}(2,78)=5.208, \quad p=.008\right)$, reflecting the increase in competition effect across sessions. This interaction did not reach significance between days 1 and 2, likely because of a small numerical difference in

Table 1

Mean RT (in ms, standard errors in parentheses) to base words in the competition tasks (pause detection in Experiments 1 and 2, semantic decision in Experiments 3 and 4). Base words in the Trained condition have acquired a novel competitor, Control words have not.

\begin{tabular}{lrll}
\hline & \multicolumn{1}{c}{ Day 1 } & \multicolumn{1}{l}{ Day2 } & \multicolumn{1}{l}{ Day8 } \\
\hline $\begin{array}{l}\text { Experiment } \\
\text { Trained }\end{array}$ & $693(21)$ & $730(28)$ & $849(34)$ \\
Control & $671(26)$ & $679(27)$ & $739(29)$ \\
Experiment & 2. Print-speech & & \\
Trained & $645(18)$ & $619(20)$ & $710(27)$ \\
Control & $646(20)$ & $622(21)$ & $671(23)$ \\
Experiment & & & \\
Trained & $772(25)$ & $763(29)$ & $880(40)$ \\
Control & $759(25)$ & $728(27)$ & $824(34)$ \\
Experiment & 4. Speech-print & & \\
Trained & $736(21)$ & $768(29)$ & $890(35)$ \\
Control & $720(24)$ & $728(24)$ & $805(26)$ \\
\hline
\end{tabular}




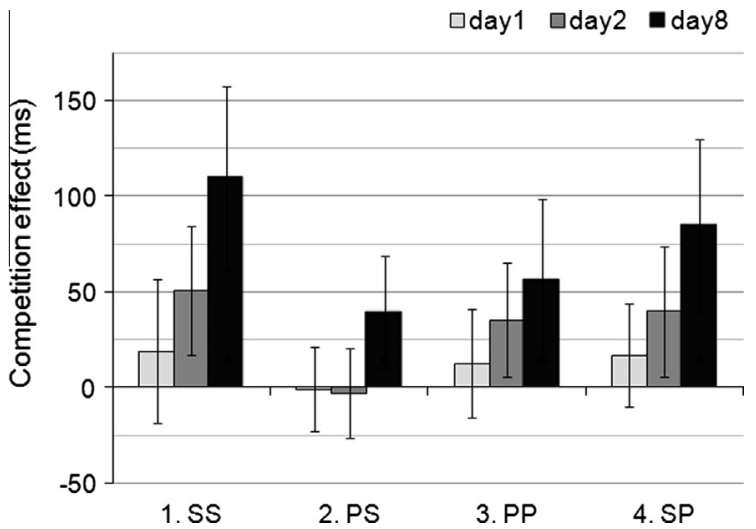

Fig. 1. Competition effects $\left(\mathrm{RT}_{\text {trained }}-\mathrm{RT}_{\text {control }}\right)$ in the competition tasks (pause detection in Experiments 1 and 2, semantic decision in Experiments 3 and 4). From left to right, the clusters refer to Experiment 1 (SS = speech training, speech test), Experiment 2 (PS = print training, speech test), Experiment 3 ( $\mathrm{PP}=$ print training, print test) and Experiment $4(\mathrm{SP}=$ speech training, print test). Error bars indicate $95 \%$ confidence intervals.

the same direction on day $1(F 1(1,25)=1.19, p=.286$; $\left.F_{2}(1,39)=1.89, p=.178\right)$. Following up on the Day $\times$ Condition interaction, we tested whether significant competition effects were present on each day. On day 1, the comparison between trained and control words did not reveal any trend towards a competition effect $\left(t_{1}(25)=1.212, p=.237\right.$; $\left.t_{2}(39)=1.412, p=.166\right)$. Significant slowing down of trained words was visible on day 2 , in contrast $\left(t_{1}(25)=3.076, p=.005 ; t_{2}(39)=3.146, p=.003\right)$, and remained on day $8\left(t_{1}(25)=4.685, p=.001 ; t_{2}(39)=4.425\right.$, $p=.001)$. These results replicate the delayed emergence of competition effects from novel words, consistent with the idea that lexicalisation requires offline consolidation (e.g. Gaskell \& Dumay, 2003).

Free recall scores improved over the course of the three sessions $(F(2,50)=51.79, p=.001)$, from an average of 7 out of 20 words recalled in the first two sessions to 11 in the final session (see Fig. 2). Paired $t$-tests revealed that there was no significant overnight change between days 1 and $2(t(25)=0.435, p=.667)$, but a significant improvement occurred between days 2 and $8(t(25)=10.147$, $p=.001)$. Performance on the 2AFC recognition task was at ceiling level, with at least 19 out of 20 correct responses on average in all sessions (see Fig. 3). There was no effect of Day on 2AFC scores in the by-subjects analysis $\left(F_{1}(2,50)=2.103, p=.147\right)$, but the by-items analysis did reveal a difference between days $\left(F_{2}(1.673,65.349)=10.73\right.$, $p=.001)$ which was driven by a drop in performance between the first and second session $\left(t_{2}(39)=1.863\right.$, $p=.017)$. Overall, the memory results illustrate the dissociation between explicit recognition/retrieval and lexical functioning. Most strikingly, the emergence of competition effects on day 2 did not co-occur with an improvement in memory performance, but rather with a worsening of recognition scores.

\section{Discussion}

Experiment 1 replicated the well-established finding that although newly learned spoken words such as

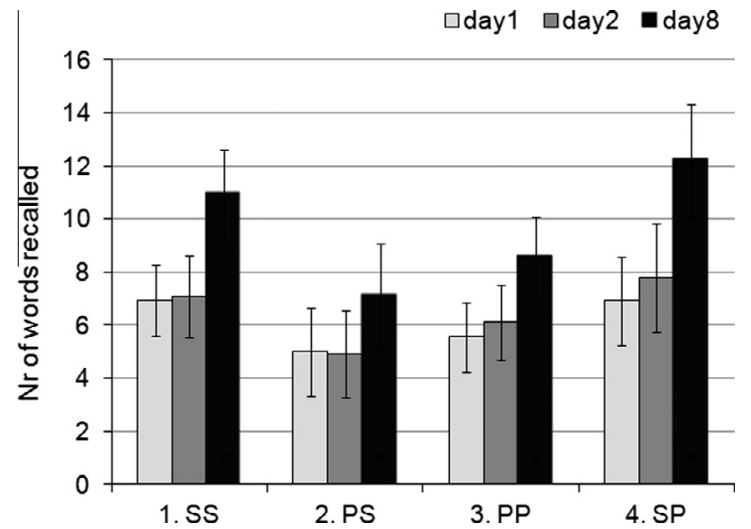

Fig. 2. Number of words correctly recalled (out of 20) in the free recall task. From left to right, the clusters refer to Experiment 1 (SS = speech training, speech test), Experiment 2 (PS = print training, speech test), Experiment 3 ( $\mathrm{PP}=$ print training, print test) and Experiment 4 ( $\mathrm{SP}=$ speech training, print test). Error bars indicate $95 \%$ confidence intervals.

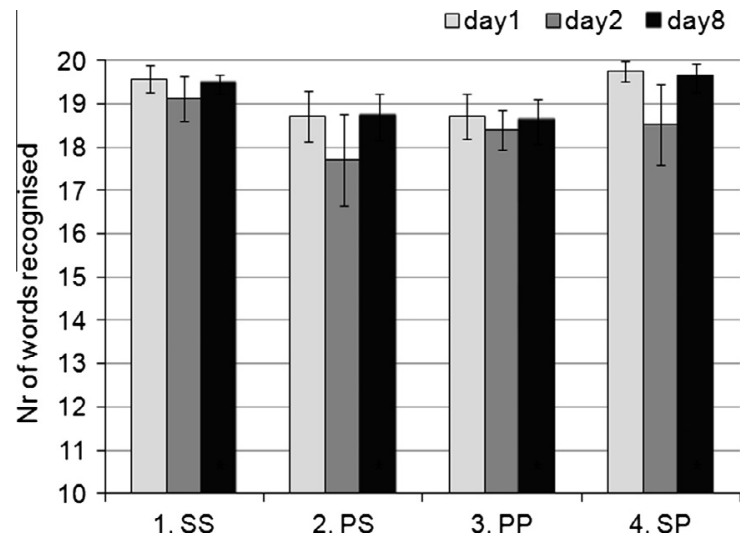

Fig. 3. Number of words correctly recognised (out of 20) in the $2 \mathrm{AFC}$ recognition task. From left to right, the clusters refer to Experiment 1 (SS = speech training, speech test), Experiment 2 (PS = print training, speech test), Experiment 3 ( $\mathrm{PP}=$ print training, print test) and Experiment $4(\mathrm{SP}=$ speech training, print test). Error bars indicate $95 \%$ confidence intervals.

kathedrook can be accurately recognised immediately after one training session, their integration into the mental lexicon requires offline consolidation (Gaskell \& Dumay, 2003). Only after $24 \mathrm{~h}$, which included a night's sleep, did these novel words engage in lexical competition with their existing phonological neighbours, suggesting that a lexicalised representation had been formed. Although competition effects were not close to significance in the first session, the direction of the numerical effect was identical across sessions and the interaction between day 1 and day 2 was not significant. This more linear increase rather than a sharp shift after $24 \mathrm{~h}$ is in line with recent work suggesting that sleep, although beneficial, is not a necessary condition for lexical integration (Lindsay \& Gaskell, 2013; Szmalec et al., 2012). However, as significant competition only emerged after a delay, the data are consistent with the more general proposition of the CLS framework that 
offline consolidation underlies the gradual integration of novel (word) memories (Davis \& Gaskell, 2009; McClelland, McNaughton, \& O'Reilly, 1995).

Competition effects continued to increase after additional training on the second day, followed by a delay of one week. Teasing apart the effects of repeated training and additional consolidation time falls outside the scope of the present study, but previous work suggests that manipulation of exposure may be most conducive to increased competition. Evidence of lexical integration has been observed in the absence of sleep when participants were exposed to both novel words and their existing neighbours in an interleaved fashion (Lindsay \& Gaskell, 2013). Given that the second training session was preceded by exposure to the base words during test, this interleaving may underlie the increased effects on day 8 . However, we cannot exclude the possibility that a consolidation period of a week, without the second training session, would have resulted in a similar increase. Another possibility is that a second training session is crucial, but that its effect only emerges after a subsequent re-consolidation period. It remains to be investigated to what degree the length of the initial consolidation period, the reconsolidation period, and spaced exposure contribute to the magnitude of competition effects, and how these factors interact.

\section{Experiment 2}

If retrieval of phonological information during printed word processing is qualitatively similar to the neural response evoked by actual speech perception, this internally generated activity may serve as input to novel word learning. In Experiment 2 we asked whether such cross-modal effects can indeed be observed, and how the time-course and magnitude of competition effects from visually acquired words compare to the pattern of results in Experiment 1 . The same procedures and items as in Experiment 1 were used, but novel words were presented only in their printed form. If printed input indeed suffices to establish lexically competing phonological representations, competition effects in the spoken modality, comparable to those in Experiment 1, would be expected to emerge on day 2 and/or day 8 .

\section{Method}

\section{Participants}

Twenty-seven participants (six males), aged 1928 years (mean 22), from the same population as Experiment 1 took part. None had participated in Experiment 1.

\section{Materials}

The materials were identical to those of Experiment 1, except that the novel word stimuli in the training phase were the printed forms of the spoken items used in Experiment 1 . Due to the relatively transparent spelling of Dutch, there was very little or no ambiguity in phonemeto-grapheme or grapheme-to-phoneme mappings for the novel items.

\section{Procedure}

The training phase consisted of a letter monitoring task, in which participants were presented with one of six target letters before each block (p,t,b,l,k,n) and pressed a button when they saw the target in a word. Targets occurred in 412 trials per block (average 7). The 20 novel words were presented for $1500 \mathrm{~ms}$ with an inter-trial interval of $1000 \mathrm{~ms}$. All other task parameters were identical to Experiment 1 . The pause detection task was administered directly following training and again on days 2 and 8 , as in Experiment 1.

The novel word memory tasks were administered in printed form, to ensure that participants did not receive any phonological input of the novel words. In the 2AFC task, the novel word and its foil (with one letter substituted) were presented randomly on the left and right side of the screen, and participants pressed the left or right button to indicate their response. In the free recall task, participants were asked to write down on a sheet of paper as many words as they remembered, within $3 \mathrm{~min}$.

\section{Results}

As in phoneme monitoring, error rates in the letter monitoring task were low (misses $1.2 \%$, false alarms $0.8 \%$ ). No effect of Day or Condition on accuracy was observed in the pause detection task. Errors (4.3\%) and RTs below $200 \mathrm{~ms}$ or above $1700 \mathrm{~ms}$ (1.7\%) were removed from the pause detection data for reaction time analysis, and pause-present and pause-absent trials were collapsed.

Base words with a novel competitor were responded to slower than control words ( $658 \mathrm{~ms}$ versus $646 \mathrm{~ms}$, an effect of $12 \mathrm{~ms}$ ). Unlike in Experiment 1, this overall effect was driven only by a $39 \mathrm{~ms}$ effect on day 8 , comparable to the $51 \mathrm{~ms}$ effect on day 2 in Experiment 1 (see Section 'Cross-experiment analyses' for an analysis across all four experiments). In contrast, in the first and second session no competition effects were observed $(-1 \mathrm{~ms}$ on day $1,-3 \mathrm{~ms}$ on day 2 ). Results are summarised in Table 1 and Fig. 1.

A main effect of Day reflected an overall slowing of RTs on day $8\left(F_{1}(2,52)=6.805, p=.002 ; F_{2}(2,78)=25.224\right.$, $p=.001)$. No main effect of Condition was found. A significant interaction of Day and Condition $\left(F_{1}(2,52)=4.154\right.$, $p=.032$; marginally significant by items: $\left.F_{2}(1.719,67.033)=3.172, p=.056\right)$ confirmed the delayed emergence of lexical competition effects. As in Experiment 1 , there was no local interaction between day 1 and 2 $\left(F_{1}(1,26)=26.5, p=.864 ; F_{2}(1,39)=33.874, \mathrm{p}=.898\right)$. On day 1 and 2, no significant difference was observed between trained and control words (day $1: t_{1}(26)=0.099$, $p=.922 ; t_{2}(39)=0.367, p=.716$, day $2: t_{1}(26)=0.265$, $\left.p=.793 ; t_{2}(39)=0.586, p=.561\right)$. In contrast, the effect on day 8 was significant $\left(t_{1}(26)=2.744, \quad p=.011\right.$; $\left.t_{2}(39)=2.092, p=.045\right)$. Thus, unlike in Experiment 1, novel words acquired from print appeared to require two training sessions and a consolidation period of a week to enter into competition, instead of $24 \mathrm{~h}$ following a single training session.

Free recall performance changed across sessions, increasing from 5 recalled words in the first two sessions 
to 7 in the last session (see Fig. 2). The effect of Day was significant $(F(2,52)=20.131, p=.001)$, with no difference occurring between day 1 and $2(t(26)=.25, p=.805)$ and a significant improvement between day 2 and 8 $(t(26)=5.544, p=.001)$. An effect of Day on 2AFC performance was also observed $\left(F_{1}(2,52)=5.949, p=.009\right.$; $\left.F_{2}(2,78)=10.108, p=.001\right)$, even though performance in all sessions was close to ceiling level (see Fig. 3). Scores decreased significantly from day 1 to day $2\left(t_{1}(26)=2.762\right.$, $\left.p=.01 ; t_{2}(39)=3.827, p=.001\right)$, and increased again on day $8\left(t_{1}(26)=2.598, p=.015 ; t_{2}(39)=3.444, p=.001\right)$. Thus, memory scores again showed the largest change between days 2 and 8, with a small drop in performance between the first two sessions.

\section{Discussion}

Experiment 2 tested whether lexical competition effects from novel orthographic neighbours can arise in a spoken task, when novel words were acquired visually. The results suggest that cross-modal lexicalisation indeed took place: novel words entered into competition in spoken word recognition, despite never having been heard. The most likely explanation is that phonological information about the novel word became available through orthographic-phonemic conversion procedures (Ferrand \& Grainger, 2003; Grainger \& Ferrand, 1994), and provided input to the phonological learning system. Thus, retrieval of phonology during reading appears to have a functional role in novel word learning, rather than being a mere epiphenomenon of cross-modal connections.

Interestingly, the emergence of these competition effects appeared to be delayed relative to those found with spoken novel word learning. Whereas in Experiment 1 auditorily acquired novel words slowed down recognition of their neighbours by $50 \mathrm{~ms}$ after $24 \mathrm{~h}$, this effect was entirely absent at the same point in time for words learned from print. The lack of any competition effects in this session indicates that lexicalisation was not yet sufficient for visually acquired novel words to engage in lexical competition with the phonological representations of their existing neighbours after $24 \mathrm{~h}$. A robust competition effect (albeit smaller than the effect on day 8 in Experiment 1 ) did however arise one week later, a period which included an additional training session on day 2 . Two factors may explain the delayed emergence of competition in the cross-modal case, relative to the within-modality results.

Firstly, printed input (or the specific task used here) could give rise to weaker memory representations in general, regardless of test modality, such that lexical competition from printed novel words requires either additional exposure, consolidation time, or both. This possibility is supported by the lower memory performance in Experiment 2 compared to Experiment 1. Free recall scores were significantly lower than in Experiment 1 on day 8 $(t(51)=3.03, p=.004)$, and 2AFC scores were lower on all days (day1: $t(40.42)=2.67, \quad p=.011 ; \quad$ day2: $t(37.95)=2.45, p=.002$; day8: $t(35.72)=2.67, p=.01)$. However, Bowers et al. (2005) reported significant competition effects on day 2 from visually acquired words in a visual lexical competition task. Although the typing task used in that study may have stimulated deeper encoding than our letter monitoring task, these results do suggest that printed input can in principle lead to competition effects after one night.

A second possibility is that the delay is due to the crossmodal design of Experiment 2, that is, the mismatch between training and test modality, rather than training modality per se. Lexicalisation of novel words may be a gradual process, giving rise to different effects at different time points. Word representations of a day old may be capable of competing only in the modality they were acquired in, as they remain partly supported by episodic memory, whereas after a week their lexicalisation is sufficient to allow for cross-modal competition. In Experiment 3 we aimed to tease apart the influence of memory strength and crossmodal consolidation on lexical competition.

\section{Experiment 3}

Experiment 3 investigated whether novel words acquired from print are able to engage with existing printed words in a visual lexical competition task. As in the pause detection task, the assumption is that lexicalised novel words slow down responses to existing neighbours, relative to neighbours without novel competitors. If, on the one hand, memory strength due to input modality is the determining factor in the overnight emergence of competition, delayed effects are expected. If, on the other hand, training in print is as effective as training in speech, and only the shift in modality creates delayed competition effects, we should observe the standard pattern of competition effects emerging on day 2 .

A third possibility is that unlike phonological representations, visually acquired representations enter into competition immediately after learning when tested in the same modality. Clay et al. (2007) reported that whilst visually acquired novel words only started to function as semantic distractors in a picture-word interference task after a week, they did inhibit their orthographic neighbours immediately after training. Furthermore, although competition effects only reached significance on day 2 , Bowers et al. (2005) observed a trend towards competition on day 1 with visually acquired novel words in a visual competition task, and no interaction between Day and Condition. These results suggest that (sleep) consolidation might play a somewhat weaker role in visual word learning compared to learning from speech. Experiment 3, in combination with Experiment 4 below, provides a direct comparison between training modalities while keeping the modality of the competition task constant.

The task used in Experiments 3 and 4 was semantic decision. This task has previously revealed competition effects for stimuli similar to ours (Bowers et al., 2005). Although the participant's response in this task is based on semantic processing of the base word, and therefore the task differs slightly from the pause detection task we used to measure spoken word competition, there is no reason to believe that any RT differences in this task between words with and without novel neighbours are caused by a different mechanism than the form-based competition that is assumed to underlie pause detection effects. Given the absence of any 
semantic context in the task, successful resolution of formlevel competition is required before response preparation can be initiated. Competition effects from novel words therefore must have their locus before semantic processes come into play. Furthermore, the novel words have no meaning association other than the meaning of their base words, which may be evoked due to their phonological/ orthographic overlap. If semantic association would have any effect on base word recognition latencies, it would likely be of a facilitative nature, as both forms activate the same conceptual representation. Any increase in RTs therefore presumably reflects competition at the form level.

In an extensive pilot, we used a non-semantic task as a visual analogue of the pause detection task, namely progressive demasking (PDM, Grainger \& Segui, 1990). Data from the PDM task, however, were highly variable and no significant competition effects were observed. A likely explanation is that identification tasks such as PDM do not provide a sensitive enough measure of competition with words of the length required for the auditory experiments (for a related argument about word length in the context of masked form priming, see Davis \& Lupker, 2006). Since the effects in spoken word recognition rely on a large distance between the original uniqueness point and the shifted uniqueness point introduced by the novel competitor, the pause detection paradigm is generally used with bi- or trisyllabic words of at least six phonemes (in the current study, items were 69 phonemes long with a mean of 7.4, and all were trisyllabic). Because similarity in stimulus sets is arguably more crucial for cross-experimental comparability than task similarity, we opted for the semantic decision task in the current design.

\section{Method}

\section{Participants}

Twenty-nine participants (five males), aged 18-26 (mean 21), from the same population as the previous experiments took part. None had participated in any previous experiments.

\section{Materials}

For the purpose of the semantic decision task, we designed a novel set of stimuli (see Appendix) that consisted of 40 words without existing orthographic neighbours. Neighbours were defined here as containing precisely one letter substitution, keeping word length and letter position constant (Coltheart, Davelaar, Jonasson, \& Besner, 1977). Of the 40 items, 20 referred to artefacts and 20 were names of naturally occurring objects. All items were bi- and trisyllabic words of 6-7 letters long, with CELEX frequencies ranging from 1 to 69 per million (mean 11). Novel words were constructed from the existing words by substituting one letter in varying positions (e.g., tomaat (tomato) - tokaat), similarly to Bowers et al. (2005). Stimuli were divided into two lists matched on frequency, length and proportion of natural/artefact words, and counterbalanced across participants. Novel word foils for the 2AFC task were created by substituting one letter of each novel word, as before.

\section{Procedure}

The training phase consisted of letter monitoring, as in Experiment 2. Due to the restrictions placed on stimulus selection by the semantic manipulation of the existing words, the number of different targets had to be increased to achieve a balanced distribution of target-present responses across items. Therefore, nine targets were each used in four blocks ( $m, t, 1, n, k, a, p, d, r)$. Each block contained 3-12 target-present trials (average 7). Otherwise, the letter monitoring, free recall and 2AFC tasks followed procedures identical to those of the corresponding tasks in Experiment 2.

In the semantic decision task, participants pressed one of two buttons to indicate whether the target word referred to an artefact or a natural object. Response button allocation was counterbalanced across participants. Words were presented until button press with a maximum response window of $2500 \mathrm{~ms}$ and an inter-trial interval of $1150 \mathrm{~ms}$. Feedback was presented after each trial. An additional 80 filler words, 40 referring to artefacts and 40 to natural objects, were included. As in the previous experiments, the training lists were counterbalanced, and thus the 20 existing words that acquired a novel neighbour for one half of the participants served as the control condition for the other participants.

\section{Results}

Letter monitoring performance was similar to Experiment 2 (misses $1.5 \%$, false alarms $0.8 \%$ ). No accuracy effects of Day or Condition were observed in semantic decision. Errors (6\%) and RTs below $200 \mathrm{~ms}$ or above $1700 \mathrm{~ms}$ (2\%) were removed from the semantic decision data for reaction time analysis. Numerical competition effects were observed on each day. Immediately after training, base words with a novel competitor were responded to $13 \mathrm{~ms}$ slower on average than control words. This competition effect increased to $35 \mathrm{~ms}$ on day 2 and $56 \mathrm{~ms}$ on day 8 , suggesting that gradual lexical integration had taken place. Results are summarised in Table 1 and Fig. 1.

A main effect of Condition (marginally significant by items) confirmed the overall presence of competition effects from novel orthographic neighbours $\left(F_{1}(1,28)=10.693\right.$, $\left.p=.003 ; F_{2}(1,39)=3.942, p=.054\right)$. A main effect of Day was also observed, reflecting general slowing down across days $\quad\left(F_{1}(2,56)=12.671, \quad p=.001 ; \quad F_{2}(2,78)=47.685\right.$, $p=.001)$. The interaction of Day and Condition did not reach significance overall $\left(F_{1}(2,56)=1.936, \quad p=.154\right.$; $\left.F_{2}(2,78)=0.873, p=.422\right)$ or within the first two sessions $\left(F_{1}(1,28)=1.698, p=.203 ; F_{2}(1,39)=2.419, p=.128\right)$. However, given that our main hypothesis concerns the presence or absence of significant competition effects on day 2 , rather than the overall change across sessions, we tested for the effect of Condition in each session as in the two previous experiments. As expected, no effect was found in the first session $\left(t_{1}(28)=0.923, p=.364 ; t_{2}(39)=0.836, p=.408\right)$. The competition effect was significant on day 2 $\left(t_{1}(28)=2.453, \quad p=.021 ; \quad t_{2}(39)=2.411, \quad p=.021\right)$, and remained present on day 8 in the by-subjects analysis $\left(t_{1}(28)=2.7, p=.012\right)$ although it did not reach significance in the by-items analysis $\left(t_{2}(39)=1.44, p=.158\right)$. Thus, 
although the effects were weaker, the results of Experiment 3 exhibited a pattern qualitatively similar to that observed in Experiment 1 (see Section 'Cross-experiment analyses' for an analysis across all four experiments). Competition effects did not emerge immediately after training, although the interaction of Day and Condition did not reach significance. However, neither was there an indication of any competition on day 1 , in contrast to the trend observed by Bowers et al. (2005). Rather, it appears that in the current experiment, print-print consolidation followed a similar time-course as consolidation from speech input.

As in previous experiments, an effect of Day on free recall scores (see Fig. 2) suggested improvement across sessions $(F(2,56)=20.901, \quad p=.001)$. No difference was observed between day 1 and $2(t(28)=1.394, p=.174)$, but performance increased between day 2 and 8 $(t(28)=4.778, p=.001)$. Performance on the 2AFC task (see Fig. 3) was close to ceiling level and did not change across sessions $\left(F_{1}(2,56)=.596, p=.555 ; F_{2}(2,78)=0.501\right.$, $p=.608)$.

\section{Discussion}

Experiment 3 employed a semantic decision task to measure the degree to which visually acquired novel words engaged in lexical competition with their existing orthographic neighbours. As in Experiment 1, but unlike in Experiment 2, the data suggested that novel words started acting as competitors after $24 \mathrm{~h}$. These findings are in line with the conclusion that lexical competition from visual input can emerge after only $24 \mathrm{~h}$ (Bowers et al., 2005), provided that modality remains constant across training and test. Effects were nonetheless statistically weaker than in Experiment 1, especially on day 8, suggesting again that print input may not be optimally suited for the formation of lexical representations.

Memory performance did not differ between the two print-learning experiments $(p>.2$ in both free recall and 2AFC on all days). The delayed emergence of competition in Experiment 2 therefore cannot solely be explained by input modality, although learning in speech may generally be superior to visual training for the formation of novel lexical memories. Crucially, the same visual input that did not produce competition in spoken word recognition on day 2 in Experiment 2 did lead to competition effects in printed word recognition in Experiment 3, without any difference in memory strength. Although such a qualitative cross-experiment comparison necessarily remains speculative, the pattern of results suggests that a modality shift between training and test influences the time course of lexicalisation. Formation of new lexical representations thus appears to be a slow and gradual process that continues to produce behavioural changes over the course of at least a week after learning.

\section{Experiment 4}

Experiment 2 revealed that novel words can engage in lexical competition in the auditory modality, despite having been encountered only in printed form, at least after a delay of more than $24 \mathrm{~h}$ and two training sessions. Given the evolutionary and developmental primacy of speech over writing, however, it seems plausible that speech input would enhance lexicalisation, and hence possibly enable cross-modal competition effects to emerge after $24 \mathrm{~h}$. While research on the effect of modality on novel word learning is rare, many studies in the educational domain do reveal an advantage of auditory input on explicit retrieval of more complex information. When participants are presented with information of an educational nature, such as facts concerning meteorology or human anatomy, auditory presentation of the instruction text generally leads to higher memory performance than visual presentation. This auditory advantage is especially prominent in paradigms using a fixed presentation rate, such as our exposure procedures, rather than self-paced tasks (for a review and meta-analysis see Ginns, 2005). In Experiment 4 we tested the hypothesis that speech input aids lexicalisation, and asked how the time-course of consolidation effects is affected when novel words are acquired from speech but competition is measured in a visual task.

\section{Method}

\section{Participants}

Twenty-five individuals (four males) aged 18-28 (mean 21 ) from the same population as in previous experiments participated. None took part in any of the previous experiments.

\section{Materials}

Recordings of the spoken forms of the novel words described in Experiment 3 were used for the training phase, and spoken forms of the novel word foils were used in the 2AFC task. Otherwise, materials were identical to those used in Experiment 3.

\section{Procedure}

The training phase on day 1 and 2 consisted of phoneme monitoring, as in Experiment 1, using targets $/ \mathrm{t} /, / \mathrm{m} /, / \mathrm{l} /$, $/ \mathrm{k} /, / \mathrm{d} /$, and $/ \mathrm{n} /$. Each block contained 4-11 trial-present trials (on average 7 ). The novel word memory tasks (free recall and 2AFC) were administered in speech, as in Experiment 1 . The semantic decision task was performed after training on day 1 and as the first task on day 2 and 8, as in Experiment 3.

Results

Phoneme monitoring performance was good (misses $0.4 \%$, false alarms $0.6 \%$ ). No effect of Day or Condition was found on error rates in the semantic decision task. Errors (5.4\%) and RTs below $200 \mathrm{~ms}$ or above $1700 \mathrm{~ms}$ (2\%) were removed from the semantic decision data for reaction time analysis. Immediately after training, RTs were on average $16 \mathrm{~ms}$ higher to words with novel competitors than to control words. This effect increased to $40 \mathrm{~ms}$ on day 2 and further to $84 \mathrm{~ms}$ on day 8 (see Table 1 and Fig. 1).

A main effect of Condition confirmed the overall presence of competition effects $\left(F_{1}(1,24)=19.376, p=.001 ; F_{2}\right.$ $(2,78)=19.94, p=.001)$. RTs increased over sessions as indicated by a main effect of Day $\left(F_{1}(2,48)=16.815\right.$, $\left.p=.001 ; F_{2}(2,78)=62.55, p=.001\right)$. The interaction of Day 
and Condition was significant $\left(F_{1}(2,48)=4.066, p=.023\right.$; $\left.F_{2}(2,78)=4.41, p=.015\right)$, indicating an increase of lexical competition after consolidation. As before, the interaction between days 1 and 2 did not reach significance independently of the day 8 data $\left(F_{1}(1,26)=.03, p=.864\right.$; $\left.F_{2}(1,39)=1.97, p=.169\right)$. The competition effect was however absent on day $1 \quad\left(t_{1}(24)=1.275, p=.215\right.$; $\left.t_{2}(39)=0.559, p=.579\right)$, and significant on day 2 $\left(t_{1}(24)=2.412, p=.024 ; t_{2}(39)=2.209, p=.033\right)$ and day $8\left(t_{1}(24)=3.862, p=.001 ; t_{2}(39)=4.421, p=.001\right)$. Thus, the overall pattern suggests that cross-modal effects can be observed after $24 \mathrm{~h}$ when encoding is sufficiently effective.

One subject was excluded from analyses involving free recall due to loss of data for one session. Free recall scores (see Fig. 2) changed significantly over sessions $(F(2,46)=26.772, p=.001)$, with no difference between day 1 and $2(t(23)=1.325, p=.198)$ and a significant increase between day 2 and $8 t(23)=5.207, p=.001)$. 2AFC scores (see Fig. 3) also changed over days $\left(F_{1}(2,48)=6.557, \quad p=.012 ; \quad F_{2}(1.317,51.381)=44.593\right.$, $p=.001)$, with a drop in performance between day 1 and 2 $\left.\left(t_{1}(24)=2.889\right), p=.008 ; t_{2}(39)=5.555, p=.001\right)$. A slight increase from day 2 to day 8 was significant by subjects $\left(t_{1}(24)=2.397, \quad p=.025\right)$ and a trend by items $\left(t_{2}(39)=1.838, p=.074\right)$

\section{Discussion}

Experiment 4 showed that novel words acquired from spoken input can engage in lexical competition with existing neighbours during printed word recognition. As in Experiment 1, lexicalisation effects emerged on day 2, suggesting that a lexical representation that is able to engage in competition with orthographic neighbours can be established after $24 \mathrm{~h}$, even in the absence of any printed input. Whereas Experiment 2 revealed that visual input can produce representations that compete in spoken as well as in printed word recognition, these cross-modal effects were delayed relative to those of Experiment 4.

Thus, although input in both modalities ultimately evoked within- and cross-modal competition effects, speech training appeared to accelerate the lexicalisation process. To quantify this interaction of training modality on the one hand and modality (mis)match between training and test on the other, we performed an overall crossexperiment analysis of competition effects and novel word memory.

\section{Cross-experiment analyses}

For ease of interpretation, we performed the RT analyses on the lexical competition effect, that is, the difference between the trained (acquired a novel neighbour) and control (no novel neighbour) condition rather than including condition as a factor. Pause detection and semantic decision may not produce competition effects of the same absolute magnitude, which makes it problematic to compare RT effects directly. In order to compare the degree to which recognition was slowed down by the introduction of a novel neighbour across tasks, change in latency was therefore computed as a ratio of RTs in the trained versus the control condition ( $\left.\left(\mathrm{RT}_{\text {trained }}-\mathrm{RT}_{\text {control }}\right) / \mathrm{RT}_{\text {control }}\right)$. For each session separately, an ANOVA with factors Training Modality and Test Modality was performed.

On day 1 , as expected given the absence of any competition (or facilitation) effects, no effects of modality were found. On day 2, we observed a main effect of Training Modality in the by-subjects analysis $\left(F_{1}(1,103)=4.714\right.$, $p=.032)$, which however did not reach significance by items $\left(F_{2}(1,156)=2.565, p=.111\right)$, and a trend towards an interaction of Training Modality by Test Modality $\left(F_{1}(1,103)=3.574, \quad p=.061\right)$, also weaker by items $\left(F_{2}(1,156)=2.239, p=.137\right)$. On day 8 , only the main effect of Training Modality was significant $\left(F_{1}(1,103)=6.548\right.$, $\left.p=.012 ; F_{2}(1,156)=4.97, p=.027\right)$. This pattern indicates that novel words engage in competition, regardless of modality, after one week and two training sessions. For cross-modal competition to emerge already on day 2 however, optimal encoding (i.e., from speech input) appears to be required.

With regard to the effect of Training Modality on novel word memory across experiments, we found that speech training led to superior free recall on each day (main effect of Training Modality on day $1: F(1,102)=5.082, p=.026$; day $2: F(1,102)=5.664, p=.019$; day $8: F(1,102)=17.459$, $p=.001)$. No main effect of Test Modality nor an interaction was found in any session, indicating that the modality of the task itself (i.e. writing down or saying aloud the novel words) did not influence free recall performance. The 2AFC task scores also revealed a main effect of Training Modality in the by-subjects analysis (day1: $F(1,103)=18.633$, $p=.001$; day $2: F(1,103)=4.041, \quad p=.047 ;$ day 8 : $F(1,103)=17.506, p=.001)$. Additionally, the main effect of Test Modality was significant in the by-items analyses (day1: $\quad F_{2}(1,156)=279.966, \quad p=.001 ; \quad$ day2: $\quad F_{2}$ $(1,156)=216.505, p=.001 ;$ day8: $F_{2}(1,156)=227.611$, $p=.001)$. The interaction of Training Modality and Test Modality reached significance by items only on day 1 $\left(F_{2}(1,156)=6.604, p=.011\right)$. Thus, enhanced memory stability resulting from spoken input likely facilitated the emergence of competition effects on day 2 .

\section{General discussion}

In four experiments, we have shown that newly acquired words are able to engage in lexical competition with existing neighbours, even when these existing words are presented in another modality than the one in which learning took place. In Experiment 1, novel words acquired from speech did not immediately affect recognition of their existing neighbours in an auditory pause detection task, but started doing so $24 \mathrm{~h}$ after learning. Competition effects continued to increase after a week, which included a second training phase after the testing session on day 2. Experiment 1 thus provided support for the claim that offline consolidation facilitates lexicalisation (Davis \& Gaskell, 2009; Dumay \& Gaskell, 2005, 2007; McClelland, McNaughton, \& O'Reilly, 1995), and showed that additional training and consolidation lead to further behavioural changes after the initial shift in representation. 
In Experiment 2, novel words engaged in competition during spoken word recognition despite having been encountered exclusively in printed form, albeit only after a week including an additional training session. In contrast, when novel words were acquired in speech, and competition was probed in a visual task, evidence of lexical integration was observed $24 \mathrm{~h}$ after training (Experiment 4 ). As confirmed by Experiment 3, the delayed emergence of competition effects from printed input cannot be explained purely by a speech-input advantage. Although visual learning appeared to hinder encoding relative to spoken input in general, it only delayed the time-course of cross-modal lexicalisation (Experiment 2), and did not prevent competition effects from emerging after $24 \mathrm{~h}$ in a visual word recognition task (Experiment 3 ). Thus, the formation of cross-modal representations appears to be a longer, more gradual process than the lexicalisation of same-modality representations, and appears to rely more heavily on optimal encoding.

Our preferred interpretation of the cross-modal competition effects is that a modality-specific representation in the untrained modality has been established, and enters into competition with its intramodal neighbours during pause detection or semantic decision. However, an alternative explanation is that the competition process during base word recognition is itself cross-modal, and does not require the formation of a representation in the untrained modality. For example, the phonologically acquired word /tokat/ may directly enter into competition with the orthographic form of its neighbour 'tomaat', without the intervention of an orthographic representation 'tokaat'. Although difficult to exclude based on the current dataset, there is no empirical support for this account from nonlearning related word recognition paradigms. A model that included such direct cross-modal inhibitory connections at the lexical level would, for instance, predict an inhibitory effect of neighbourhood density on auditory word recognition. In contrast, facilitatory effects of cross-modal neighbourhood density are generally observed in both modalities when intramodal neighbourhood density is controlled for (Yates et al., 2004; Ziegler et al., 2003). Similarly, the addition of a phonological neighbour /tokat/ to 'tomaat', whilst keeping its orthographic neighbourhood constant, should result in facilitation of 'tomaat' rather than the inhibition we observed. Therefore, we argue that these data are best explained by a model that includes only intramodal lateral inhibitory connections, such as the Bimodal Interactive Activation model (Ferrand \& Grainger, 2003; Grainger \& Ferrand, 1994).

The observed time course of lexical competition is consistent with the Complementary Learning Systems (CLS) account of word learning (Davis \& Gaskell, 2009; McClelland, McNaughton, \& O’Reilly, 1995; Takashima, Bakker, Van Hell, Janzen, \& McQueen, 2014). On this view, newly formed word representations are episodic in nature, and rely on the hippocampal memory system for initial retrieval. During post-learning consolidation, novel memories are integrated into the distributed neocortical memory network. Hippocampal traces decay over time, leading to a loss of episodic information in return for increasingly stable, integrated and generalised neocortical representa- tions. In the context of word learning, neocortical integration allows novel words to affect retrieval of their existing neighbours, for example by engaging in competition for selection during word recognition. The present finding that competition arises even when the input and test materials do not share any perceptual features provides strong evidence that these competition effects do not rely on episodic memory, but instead on abstract, lexicalised representations.

The crux of the CLS model as outlined by McClelland et al. (1995) is the dissociation between the time-courses that characterise the hippocampal and neocortical systems, which creates the circumstances that allow gradual interleaving of old and new information. Sleep is only one of the states during which this interaction process or 'reinstatement' occurs: 'We assume that reinstatement also occurs in off-line situations, including active rehearsal, reminiscence, and other inactive states including sleep.' (McClelland et al., 1995, p. 424). In recent years sleep has acquired a more prominent role in the literature on linguistic memory consolidation, and there is indeed strong evidence to support its beneficial effect (Dumay \& Gaskell, 2007; Tamminen, Lambon Ralph, \& Lewis, 2013; Tamminen et al., 2010). At the same time, a body of evidence now suggests that given the right encoding conditions, sleep is not a necessary condition for lexicalisation. Implicit learning paradigms such as the Hebbian learning task employed by Szmalec et al. (2012), paradigms in which old and new information is explicitly interleaved (Lindsay \& Gaskell, 2013), and even phoneme monitoring (Tamminen et al., 2010) have resulted in competition effects in the absence of sleep. Although in the current work no significant competition effects arose before sleep, the lack of an interaction of Condition and Day within the first two sessions ties in with the idea that a step-like, sleep-dependent shift in the nature of novel representations may not always occur. The relative contribution of sleep and wakeful consolidation, the conditions under which wakeful consolidation is sufficient for lexicalisation, and on what time scale this process can be observed are issues that clearly warrant more research. Nonetheless, the absence (to date) of lexicalisation effects immediately following training and the consistently reported increase in effects after a delay support the core proposition of the CLS model, namely that post-encoding interaction between the fast-learning hippocampal system and the slower-learning neocortex enables interleaved memory integration.

An alternative explanation for the emergence of competition effects after consolidation has been offered by Qiao, Forster, and Witzel (2009). These authors argued that effects such as those found in the visual domain by Bowers et al. (2005) do not arise from lexical competition, but can be explained more parsimoniously by a post-access checking process that verifies whether a stimulus is in fact the base word or a highly similar novel word. In support of this argument, the authors showed that novel words continued to facilitate recognition of their neighbours in a masked priming task. This suggests that rather than functioning as real, lexicalised words, the novel word representations remained episodic in nature. Although not explicitly mentioned, in this account consolidation of the 
episodic trace presumably causes the delayed emergence of 'competition' effects in tasks like pause detection, rendering the concept of lexicalisation unnecessary. Whilst episodic memory consolidation may certainly play a role in word learning, and episodic representations may enhance the effects contributed to lexical competition, it is unlikely that episodic memory consolidation alone is responsible for the observed data patterns for the following reasons.

First, the episodic account predicts that competition effects should co-occur with memory improvements, since especially recognition memory tasks rely heavily on episodic memory. Indeed, some studies have observed improvements in 2AFC performance (e.g. Dumay \& Gaskell, 2007, 2012). However, there is no evidence of memory improvement between days 1 and 2 in the current dataset. Instead, three of the four experiments showed a significant drop in recognition performance on day 2, nonetheless cooccurring with the emergence of competition effects. Second, in recent work by Qiao and Forster (2012) the inhibition effect of masked novel word primes that was not observed in their earlier study did emerge after more elaborate training, which suggests that masked priming may simply be less sensitive to the small effects of early lexicalisation than tasks like pause detection or semantic decision. Third, evidence against the Qiao et al. (2009) claim comes from a word-segmentation paradigm employed by Dumay and Gaskell (2012), in which the episodic and lexical consolidation accounts predict opposite patterns. In this paradigm, subjects learned novel words in which existing words were embedded, e.g. 'lirmucktoze'. Whereas the episodic account predicts that spotting 'muck' in a sequence like 'lirmuckt' should be facilitated by the episodic memory of 'lirmucktoze', the data reveal inhibitory effects on day 2 , in line with the lexicalisation account. In sum, evidence from a variety of tasks now suggests that lexical rather than episodic representations are responsible for (at least part of) the competition effects in the literature.

How does consolidation change the nature of word memories to accommodate modality-independent competition? Many models of the mental lexicon distinguish between a level of modality-specific word forms or lexemes on the one hand, and a level of amodal lemmas and/or conceptual representations on the other hand (e.g. Bock, 1986; Dell, 1986; Garrett, 1975; Grainger \& Ferrand, 1994; Norris, Cutler, McQueen, \& Butterfield, 2006; Roelofs, 1992). In this framework, one possible explanation is that in the process of consolidation, novel words acquire an amodal lemma representation which no longer contains detailed episodic information about initial exposure conditions. This amodal representation would be able to engage in competition both in spoken and printed word recognition, regardless of modality consistency between training and test phases. Given that abstraction and generalisation of memory traces are important aspects of sleep-dependent consolidation (for a review, see Stickgold \& Walker, 2013), such a process would be in line with the idea that word learning is supported by general mechanisms of memory consolidation.

If training and subsequent consolidation conditions are optimal, new amodal lemma representations may be formed after $24 \mathrm{~h}$, as in our Experiments 1, 3 and 4, or in some cases even before sleep (Lindsay \& Gaskell, 2013; Szmalec et al., 2012). When encoding is suboptimal, however, as appeared to be the case in our print training procedure, the process may not yet be completed on the second day but require an additional delay of up to a week. Partly modality-specific representations may already engage in competition after $24 \mathrm{~h}$ when modality is constant across training and test (Experiments 1 and 3), but not when a modality shift occurs (Experiment 2). This hypothesis would explain the lack of competition effects on day 2 in Experiment 2, where weaker encoding was combined with a training-test modality change.

However, a model that attributes competition effects purely to lemma formation is difficult to integrate with the accepted view of form-based competition, which is thought to occur at the modality-specific lexeme level rather than between amodal lemmas (McQueen, 2007). Thus, in order to engage in lexical competition during visual word recognition, a novel word needs to have acquired an orthographic lexeme, and, likewise, a phonological lexeme is necessary to compete in auditory word recognition. The presence of cross-modal competition effects, albeit delayed under certain circumstances, suggests that such modality-specific representations can be formed without any input in that modality. These internally generated representations must therefore rely on the mapping of perceived speech sounds to their corresponding graphemes, and vice versa, via a sublexical conversion mechanism that may be active during encoding (e.g. Ferrand \& Grainger, 2003; Grainger \& Ferrand, 1994).

Results from pseudoword priming and recognition indicate that automatic sublexical conversion occurs during pseudoword processing (for discussion, see Taft, 2011). For example, auditory presentation of the pseudoword /swæp/, most plausibly spelled swap, primed recognition of swap in an auditory lexical decision task (Taft et al., 2008). Since no lexical representation of /swæp/ exists, this effect must stem from sublexical conversion. The fact that priming effects were observed by Taft et al. (2008) with masked primes suggests that this process can be highly automatic and subconscious. These findings support the idea that cross-modal conversion of novel words most likely took place during the processing of the novel words in our phoneme/letter monitoring tasks. This internal conversion process appeared to result in stable modality-specific lexical representations, suggesting that the representations created by sublexical conversion procedures are highly similar to those arising from the actual perceptual input. Automatic sublexical conversion may therefore not merely be epiphenomenal, but in fact play an important role in novel word learning.

In the current experiments, novel word processing of course served an intentional memory encoding purpose as well as mere lexical access, unlike in the non-learning experiments discussed above. For this reason, subjects may have deliberately used their sublexical conversion process to aid encoding as well as phoneme/letter monitoring. This could in turn have enhanced cross-modal memory formation. The current data do not allow us to assess the relative contribution of strategic factors, but the use of an 
implicit encoding paradigm that placed no emphasis on the sublexical level might help to disentangle the effects of automatic and deliberate conversion in the future.

Especially if subjects did indeed engage in deliberate conversion, it is furthermore plausible that they used their language production system to boost encoding. For instance, overt or covert speech production may have served as input to the phonological learning system during exposure in the visual training experiments. However, it is unlikely that production alone is responsible for the emergence of cross-modal representations, given the previously discussed evidence that sublexical conversion occurs rapidly and automatically. Moreover, if cross-modal encoding relied on degree of overt production, stronger cross-modal effects would be expected from print learning than from speech learning, since subjects who learned from print could produce overt speech if they chose to do so, whereas speechlearning subjects were only able to generate covert orthographic output (i.e. visualising the spelling of the words). The observed pattern contradicts this prediction; crossmodal lexicalisation effects were larger and emerged earlier when the input was auditory rather than visual.

The fact that sublexical conversion probably does not depend entirely on awareness raises the interesting possibility that conversion may not only be active during exposure, but that the same mechanism may also be involved during offline memory consolidation. A wealth of evidence indicates that sleep can produce qualitative memory changes, effectively adding information to what has been perceived while participants were awake. For example, sleep has been shown to induce false memories based on logical inference (Payne et al., 2009). A recent study even provided the first piece of evidence that humans are capable of learning completely novel information during sleep (Arzi et al., 2012). Thus, a speculative hypothesis is that the formation of a modality-specific lexeme in one modality during encoding may give rise to the emergence of its counterpart in the other modality during offline consolidation. Specifically, replay of newly learned printed words during sleep could evoke automatic grapheme-to-phoneme conversion, thus activating phonological sublexical representations. The resulting pattern of activation may in turn give rise to a phonological lexical representation, and similarly in the other direction for newly learned spoken words. The current data do not allow us to quantify the relative contribution of online and offline sublexical conversion. Although it is difficult to probe conversion directly during sleep, further research might be able to limit the role of online conversion by using distractor tasks in the other modality during letter/phoneme monitoring.

A testable prediction that follows from the hypothesis that sublexical conversion (either during encoding, consolidation, or both) underlies the formation of cross-modal representations is that orthographic transparency would affect the strength of the resulting representation. A sequence of sounds that could only plausibly be spelled in a single way in the listener's native writing system should lead to the generation of only one orthographic representation. Upon hearing an ambiguous item, in contrast, a listener could form a representation that does not match the subsequent visual input, or alternatively form several candidate repre- sentations which may each produce weaker effects. By extension, cross-linguistic differences in the magnitude of cross-modal lexicalisation effects would be expected to arise based on variation in orthographic transparency. Unfortunately, the current dataset does not allow for analysis of this factor due to the high transparency and consistency of the Dutch stimuli, both from sound to spelling and the reverse. However, such a comparison between items could certainly be made in English or other relatively opaque writing systems.

Although we have argued that form-based competition effects require the creation of a modality-specific lexeme, likely supported by sublexical conversion when perceptual input in the relevant modality was absent, the possibility that lemma formation plays a role in this process should not be excluded. Delayed consolidation effects have been observed in the context of semantic as well as form-based integration of novel words (Clay et al., 2007; Tamminen \& Gaskell, 2012). Indeed, some evidence suggests that sleep spindles and slow-wave activity during sleep are directly related to semantic integration (Tamminen et al., 2013). Given that semantic effects are generally thought to arise from lemma interaction (Roelofs, 1992), these findings suggest that offline consolidation and possibly sleep play a crucial role in the creation of novel lemmas. The presence of a lemma may also aid, or even be necessary for, the lexical integration of modality-specific representations of word forms, for instance by providing a link with the existing lexicon that serves to bind activated sublexical units into a stable pattern. It remains an open question whether lemma formation occurs in the absence of semantic context, and to what extent it contributes to consolidation effects on form-based competition.

In conclusion, the current experiments provide a first demonstration of lexical memory formation across modalities. The data strongly support the CLS account of word learning (Davis \& Gaskell, 2009; McClelland et al., 1995), as lexical competition was shown to arise in the absence of episodic overlap between trained novel words and test stimuli: words that were never heard before entered into competition in spoken word recognition, and words that were never seen before inhibited their orthographic neighbours during reading. These cross-modal effects are hypothesised to rely on the cortical integration of modality-specific lexemes that emerge from sublexical phoneme-grapheme conversion during novel word encoding. The conversion process may continue offline, possibly during sleep, likely in combination with the formation of amodal lemma representations. Thus, we may not only integrate information we have encountered in the outside world, but even information our brain itself has generated in the absence of any perceptual input.

\section{Acknowledgments}

This research is funded by The Netherlands Organization for Scientific Research (NWO) Brain and Cognition Grant No. 433-09-239. The authors thank Anne Castles, Mike Page, and Nicolas Dumay for their helpful comments, and Angela de Bruin and Michal Czaplinski for their help with running the experiments. 


\section{Appendix}

Stimuli used in Experiments 1 and 2.

\begin{tabular}{llllll}
\hline Novel word & Base word & English translation & Novel word & Base word & English translation \\
\hline abrikaag & abrikoos & apricot & krokodaft & krokodil & crocodile \\
alcohin & alcohol & alcohol & labyrijf & labyrint & labyrinth \\
ananol & ananas & pineapple & lavendam & lavendel & lavender \\
bacteraf & bacterie & bacterium & lucifin & lucifer & matchstick \\
batterax & batterij & battery & mandarees & mandarijn & clementine \\
bavieet & baviaan & baboon & marathil & marathon & marathon \\
bioscaag & bioscoop & cinema & microfeer & microfoon & microphone \\
bruidegant & bruidegom & bridegroom & molecomp & molecuul & molecule \\
carnavip & carnaval & carnival & olifoes & olifant & elephant \\
diameek & diamant & diamond & ooievim & ooievaar & stork \\
ellebuks & elleboog & elbow & pantoffik & pantoffel & slipper \\
flamingap & flamingo & flamingo & papegoen & papegaai & parrot \\
hagedop & hagedis & lizard & paprikoon & paprika & pepper \\
horizal & horizon & horizon & perkamees & perkament & parchment \\
horoscaag & horoscoop & horoscope & porseloft & porselein & porcelain \\
hyaceep & hyacint & hyacinth & republaan & republiek & republic \\
kaboutif & kabouter & gnome & satelloer & satelliet & satellite \\
kathedroon & kathedraal & cathedral & schorpiast & schorpioen & scorpion \\
klarinook & klarinet & clarinet & spinazep & spinazie & spinach \\
kolibraag & kolibrie & hummingbird & zeppelof & zeppelin & zeppelin \\
\hline
\end{tabular}

Stimuli used in Experiments 3 and 4.

\begin{tabular}{llllll}
\hline Novel word & Base word & English translation & Novel word & Base word & English translation \\
\hline amindel & amandel & almond & lamboe & bamboe & bamboo \\
ananak & ananas & pineapple & lumifer & lucifer & matchstick \\
baliaan & baviaan & baboon & matral & matras & mattress \\
birini & bikini & bikini & meufel & meubel & furniture \\
cadino & casino & casino & minella & mitella & sling \\
catera & camera & camera & moeran & moeras & swamp \\
dollijn & dolfijn & dolphin & mulkaan & vulkaan & volcano \\
drespel & drempel & doorstep & olipant & olifant & elephant \\
emiket & etiket & label & pargum & parfum & perfume \\
emster & ekster & magpie & perdik & perzik & peach \\
endelop & envelop & envelope & ragijn & ravijn & ravine \\
exaren & examen & exam & riviet & rivier & river \\
fengst & hengst & stallion & romonde & rotonde & roundabout \\
hamedis & hagedis & lizard & sigaam & sigaar & cigar \\
harlas & harnas & armour & stelet & skelet & skeleton \\
hirizon & horizon & horizon & tachel & kachel & heater \\
jeneker & jenever & gin & tafijt & tapijt & carpet \\
kompal & kompas & compass & tokaat & tomat & tomato \\
kwaluw & zwaluw & swallow & torkado & tornado & tornado \\
lakine & lawine & avalanche & tunsel & tunnel & tunnel \\
\hline
\end{tabular}

\section{References}

Arzi, A., Shedlesky, L., Ben-Shaul, M., Nasser, K., Oksenberg, A., Hairston, I. S., et al. (2012). Humans can learn new information during sleep. Nature Neuroscience, 15, 1460-1465.

Baayen, R. H., Piepenbrock, R., \& Gulikers, L. (1995). The CELEX lexical database [webcelex]. Philadelphia, PA: University of Pennsylvania, Linguistic Data Consortium.
Bock, J. K. (1986). Meaning, sound, and syntax: Lexical priming in sentence production. Journal of Experimental Psychology: Learning, Memory and Cognition, 12, 575-586.

Bowers, J. S., Davis, C. J., \& Hanley, D. A. (2005). Interfering neighbours: The impact of novel word learning on the identification of visually similar words. Cognition, 97, B45-54.

Caramazza, A. (1997). How many levels of processing are there in lexical access? Cognitive Neuropsychology, 14, 177-208. 
Carey, S., \& Bartlett, E. (1978). Acquiring a single new word. Papers and Reports on Child Language Development, 15, 17-29.

Chéreau, C., Gaskell, M. G., \& Dumay, N. (2007). Reading spoken words: Orthographic effects in auditory priming. Cognition, 102, 341-360.

Clay, F., Bowers, J. S., Davis, C. J., \& Hanley, D. A. (2007). Teaching adults new words: The role of practice and consolidation. Journal of Experimental Psychology: Learning, Memory, and Cognition, 33, 970-976.

Coltheart, M., Davelaar, E., Jonasson, J., \& Besner, D. (1977). Access to the internal lexicon. In S. Dornick (Ed.). Attention and performance (Vol. VI). Hillsdale, NJ: Lawrence Erlbaum Associates Inc.

Davis, M. H., Di Betta, A. M., Macdonald, M. J. E., \& Gaskell, M. G. (2009). Learning and consolidation of novel spoken words. Journal of Cognitive Neuroscience, 21(4), 803-820.

Davis, M. H., \& Gaskell, M. G. (2009). A complementary systems account of word learning: Neural and behavioural evidence. Philosophical Transactions of the Royal Society B, 364, 3773-3800.

Davis, C. J., \& Lupker, S. J. (2006). Masked inhibitory priming in English: Evidence for lexical inhibition. Journal of Experimental Psychology: Human Perception and Performance, 32, 668-687.

Dell, G. S. (1986). A spreading-activation theory of retrieval in sentence production. Psychological Review, 93, 283-321.

Dumay, N., \& Gaskell, M. G. (2005). Do words go to sleep? Exploring consolidation of spoken forms through direct and indirect measures. Behavioural and Brain Sciences, 28, 69-70.

Dumay, N., \& Gaskell, M. G. (2007). Sleep-associated changes in the mental representation of spoken words. Psychological Science, 18 35-39.

Dumay, N., \& Gaskell, M. G. (2012). Overnight lexical consolidation revealed by speech segmentation. Cognition, 123, 119-132.

Ferrand, L., \& Grainger, J. (1992). Phonology and orthography in visual word recognition: Evidence from masked non-word priming. Quarterly Journal of Experimental Psychology, 45, 353-372.

Ferrand, L., \& Grainger, J. (2003). Homophone interference effects in visual word recognition. Quarterly Journal of Experimental Psychology, 56, 403-419.

Garrett, M. F. (1975). The analysis of sentence production. In G. H. Bower (Ed.). The psychology of learning and motivation (Vol. 9, pp. 133-177). New York: Academic Press.

Gaskell, M. G., \& Dumay, N. (2003). Lexical competition and the acquisition of novel words. Cognition, 89, 105-132.

Ginns, P. (2005). Meta-analysis of the modality effect. Learning and Instruction, 15, 313-331.

Grainger, J., \& Ferrand, L. (1994). Phonology and orthography in visual word recognition: Effects of masked homophone primes. Journal of Memory and Language, 33, 218-233.

Grainger, J., Muneaux, M., Farioli, F., \& Ziegler, J. C. (2005). Effects of phonological and orthographic neighbourhood density interact in visual word recognition. Quarterly Journal of Experimental Psychology, 58, 981-998.

Grainger, J., \& Segui, J. (1990). Neighborhood frequency effects in visual word recognition: A comparison of lexical decision and masked identification latencies. Perception \& Psychophysics, 47, 191-198.

Henderson, L. M., Weighall, A., \& Gaskell, G. M. (2013). Learning new vocabulary during childhood: Effects of semantic training on lexical consolidation and integration. Journal of Experimental Child Psychology, 116, 572-592.

Lindsay, S., \& Gaskell, M. G. (2013). Lexical integration of novel words without sleep. Journal of Experimental Psychology: Learning, Memory, and Cognition, 39, 608-622.

Mattys, S. L., \& Clark, J. H. (2002). Lexical activity in speech processing: Evidence from pause detection. Journal of Memory and Language, 47 343-359.

McClelland, J. L., McNaughton, B. L., \& O’Reilly, R. C. (1995). Why there are complementary learning systems in the hippocampus and neocortex: Insights from the successes and failures of connectionist nodels of learning and memory. Psychological Review, 102, 419-457.

McCloskey, M., \& Cohen, N. J. (1989). Catastrophic interference in connectionist networks: The sequential learning problem. In $\mathrm{H}$. B. Gordon (Ed.). Psychology of learning and motivation (Vol. 24, pp. 109-165). New York: Academic Press.

McQueen, J. M. (2007). Eight questions about spoken-word recognition. In M. G. Gaskell (Ed.), The Oxford handbook of psycholinguistics (pp. 37-53). Oxford: Oxford University Press.
McQueen, J. M., Norris, D., \& Cutler, A. (1994). Competition in spoken word recognition: Spotting words in other words. Journal of Experimental Psychology: Learning, Memory and Cognition, 20, 621-638.

Norris, D., Cutler, A., McQueen, J. M., \& Butterfield, S. (2006). Phonological and conceptual activation in speech comprehension. Cognitive Psychology, 53, 146-193.

Payne, J. D., Schacter, D. L., Propper, R., Huang, L., Wamsley, E., Tucker, M A., et al. (2009). The role of sleep in false memory formation. Neurobiology of Learning and Memory, 92, 327-334.

Qiao, X., \& Forster, K. I. (2012). Novel word lexicalization and the prime lexicality effect. Journal of Experimental Psychology: Learning, Memory, and Cognition, 39, 1064-1074.

Qiao, X., Forster, K. I., \& Witzel, N. (2009). Is banara really a word? Cognition, 113, 254-257.

Rasch, B., Büchel, C., Gais, S., \& Born, J. (2007). Odor cues during slowwave sleep prompt declarative memory consolidation. Science, 315 , 1426-1429.

Rastle, K., \& Brysbaert, M. (2006). Masked phonological priming effects in English: Are they real? Do they matter? Cognitive Psychology, 53, 97-145.

Roelofs, A. (1992). A spreading-activation theory of lemma retrieval in speaking. Cognition, 42, 107-142.

Saffran, J. R., Newport, E. L., Aslin, R. N., Tunick, R. A., \& Barrueco, S. (1997). Incidental language learning: Listening (and learning) out of the corner of your ear. Psychological Science, 8, 101-105.

Shtyrov, Y., Nikulin, V. V., \& Pulvermüller, F. (2010). Rapid cortical plasticity underlying novel word learning. Journal of Neuroscience, 30 , 16864-16867.

Slowiaczek, L. M., Soltano, E. G., Wieting, S. J., \& Bishop, K. L. (2003). An investigation of phonology and orthography in spoken-word recognition. Quarterly Journal of Experimental Psychology, 56, 233-262.

Stickgold, R., \& Walker, M. P. (2013). Sleep-dependent memory triage: Evolving generalization through selective processing. Nature Neuroscience, 16, 139-145.

Szmalec, A., Page, M. P. A., \& Duyck, W. (2012). The development of longterm lexical representations through Hebb repetition learning. Journal of Memory and Language, 67, 342-354.

Taft, M. (2011). Orthographic influences when processing spoken pseudowords: Theoretical implications. Frontiers in Psychology, 2, 1-7.

Taft, M., Castles, A., Davis, C., Lazendic, G., \& Nguyen-Hoan, M. (2008). Automatic activation of orthography in spoken word recognition Pseudohomograph priming. Journal of Memory and Language, 58, 366-379.

Takashima, A., Bakker, I., Van Hell, J. G., Janzen, G., \& McQueen, J M. (2014). Richness of information about novel words influences how episodic and semantic memory networks interact during lexicalization. Neuroimage, 84, 265-278.

Tamminen, J., \& Gaskell, M. G. (2008). Newly learned spoken words show long-term lexical competition effects. Quarterly Journal of Experimental Psychology, 61, 361-371.

Tamminen, J., \& Gaskell, M. G. (2012). Novel word integration in the mental lexicon: Evidence from unmasked and masked semantic priming. Quarterly Journal of Experimental Psychology, 66, 37-41.

Tamminen, J., Lambon Ralph, M. A., \& Lewis, P. A. (2013). The role of sleep spindles and slow-wave activity in integrating new information in semantic memory. Journal of Neuroscience, 33, 15376-15381.

Tamminen, J., Payne, J. D., Stickgold, R., Wamsley, E. J., \& Gaskell, M. G. (2010). Sleep spindle activity is associated with the integration of new memories and existing knowledge. Journal of Neuroscience, 30, $14356-14360$.

Wilson, M. A., \& McNaughton, B. L. (1994). Reactivation of hippocampal ensemble memories during sleep. Science, 265, 676-679.

Yates, M., Locker, L., \& Simpson, G. B. (2004). The influence of phonological neighborhood on visual word perception. Psychonomic Bulletin E' Review, 11, 452-457.

Ziegler, J. C., Ferrand, L., Jacobs, A. M., Rey, A., \& Grainger, J. (2000). Visual and phonological codes in letter and word recognition: Evidence from incremental priming. Quarterly Journal of Experimental Psychology, 53, 671-692.

Ziegler, J. C., Muneaux, M., \& Grainger, J. (2003). Neighborhood effects in auditory word recognition: Phonological competition and orthographic facilitation. Journal of Memory and Language, 48, 779-793. 